\title{
Indomethacin for refractory COVID or post-COVID headache: a retrospective study
}

\author{
Abouch V. Krymchantowski ${ }^{1}$. Raimundo Pereira Silva-Néto ${ }^{2}$ (D) Carla Jevoux ${ }^{1} \cdot$ Ana Gabriela Krymchantowski $^{1}$
}

Received: 10 June 2021 / Accepted: 26 August 2021 / Published online: 21 September 2021

(c) Belgian Neurological Society 2021

\begin{abstract}
Background COVID-19, a disease caused by SARS-CoV-2, manifests with headache, both in the acute phase and as a postinfection symptom, which may be refractory to usual analgesics.

Objectives Investigate the therapeutic response of refractory COVID or post-COVID headache to indomethacin.

Methods This was an observational, retrospective, open and uncontrolled. A sample of 37 patients diagnosed with COVID-19 presenting headache during the acute phase or after the resolution of the disease, with refractoriness to the usual symptomatic medication was treated with indomethacin.

Results Of the 37 patients ( 24 women and 13 men), 29 were migraineurs and 8 had no previous history of headache. The average age was $40.4 \pm 9.4$ years, ranging from 19 to 65 years. In $26(70.3 \%)$ patients, the onset of headache occurred within $72 \mathrm{~h}$, and in $11(29.7 \%)$, after 10 days of positivity for Sars-CoV-2. After treatment with indomethacin, 36 patients reported greater than $50 \%$ headache relief from the third day and 5 became asymptomatic on the fifth day.

Conclusions In patients with migraine or no prior history of headache who present with refractory COVID or post-COVID headache to common analgesics, anti-inflammatory drugs, and/or triptans, indomethacin should be considered a therapeutic option.
\end{abstract}

Keywords Post-COVID headache $\cdot$ Refractory headache $\cdot$ Abortive treatment $\cdot$ Indomethacin

\section{Introduction}

Corona Virus Disease (COVID-19) is a disease caused by the newly identified human coronavirus (HCoV) named Severe Acute Respiratory Syndrome Coronavirus-2 (SARSCoV-2) $[1,2]$. It has been a global pandemic since March 2020. Although it affects primarily the respiratory system, the loss of taste and smell, dizziness, encephalitis, encephalopathy, and cerebrovascular diseases are being frequently described as neurological symptoms or complications [1-3]. Headache, during the acute phase as well as manifesting as a post-infection symptom, has also been commonly reported $[4,5]$. It affects $6.5-34 \%$ of COVID patients and may represent the only clinical manifestation [1-4]. Despite its high

Raimundo Pereira Silva-Néto

netoesperantina@terra.com.br

Headache Center of Rio, Rio de Janeiro, Brazil

2 Federal University of Delta of Parnaíba, Avenida São Sebastião, 2819/Fátima, Parnaíba, Brazil prevalence, the management of this feature remains a challenge and little published evidence on the pharmacological treatment of COVID-19 headache is available. Non-steroidal anti-inflammatory drugs (NSAID) have been suggested, at least during the acute phase, but with anecdotal results [1, $2,5,6]$.

Indomethacin is a traditional NSAID with effective analgesic, antipyretic and anti-inflammatory activity [7]. It is an indole-acetic acid derivative available since the 1960s and probably one of the most potent compounds also derived from the acetic acid as diclofenac and sulindac. Not surprisingly, indomethacin was among the first NSAID used to treat headache in clinical practice including migraine and headache syndromes eventually known as "indomethacinresponsive" headaches [7].

In addition to the inhibition of cyclooxygenase, preventing the production of prostaglandins from arachidonic acid, indomethacin has a unique action that is not yet clarified. It may interfere with iontophoresed glutamate-activated duralresponsive second order neurons in the Trigeminal Nucleus Caudalis (TCC) [8]. Moreover, indomethacin may modulate 
nitric oxide (NO) signaling pathways. Nitric oxide is known to induce headache and delayed migraine in patients $[9,10]$. In preclinical studies, indomethacin is able to inhibit NOinduced dural vasodilation [11], and this effect is unique because other NSAID also used for migraine such as naproxen or ibuprofen were ineffective in this regard [12].

COVID patients may have or not migraine as a comorbidity [1]. In addition, headache may occur during or after COVID with no clear relationship with migraine mechanisms $[1,13,14]$. However, some patients with migraine and COVID may seek help in general practitioners or emergency departments and receive unspecific prescriptions for the headache itself. Others will try using their usual acute migraine medications seeking to alleviate the head pain [13-16].This retrospective study aimed at describing the outcomes of indomethacin use in patients, with or without migraine, who presented headache not responding to their acute medication during COVID acute phase or after $>10$ days of confirmed infection by SARS-CoV- 2 .

\section{Methods}

\section{Study design and participants}

This was an observational, retrospective, open, uncontrolled, and descriptive study. The study population comprised a non-random and convenience sampling, consisting of consecutive patients with and without migraine seeking help at a tertiary headache center, to whom indomethacin was prescribed. Data for this study were collected from October 2020 to April 2021.

\section{Inclusion and exclusion criteria}

Patients over 18 years of age diagnosed with COVID-19, through the RT-PCR positivity for SARS-CoV-2 and presenting headache during the acute phase or after the resolution of the disease, with refractoriness to the usual symptomatic medication or to a symptomatic medication recently prescribed, for at least three days, were included in this study. The study excluded patients with acute headaches from secondary causes, such as acute glaucoma or acute sinusitis, and over the age of 60 years and pregnant women.

\section{Data collection}

Patients were divided into two groups: in group 1, those diagnosed with migraine without aura, according to ICHD-3 criteria [17], presenting less than 15 days of headache per month and in group 2, patients with no previous history of headache.
Indomethacin was prescribed at a dose of $50 \mathrm{mg}$, twice a day, orally, for 5 days, associated with pantoprazole $40 \mathrm{mg} /$ day for all patients. Frequency and intensity of headache were assessed on the third and fifth days of treatment using a headache diary. We used a visual analog scale (VAS) to classify the intensity of pain as VAS 1-4 (mild), VAS 5-7 (moderate), VAS 8-9 (severe), and VAS 10 (very severe).

\section{Ethical considerations}

This study was approved by the Ethics in Research Involving Human Subjects Committee at the Federal University of Piauí, Brazil, protocol number 3.276.516 and the Presentation Certificate to Ethics Assessment, registry number 08973419.0.0000.5214, on August 22, 2020.

\section{Statistical analysis}

All collected data were organized in data base. The Statistical Package for Social Sciences (SPSS ${ }^{\circledR}$ ) version 18.2.2 for statistical analysis was used. The quantitative variables were expressed as mean, standard deviation and minimum and maximum values, while qualitative variables were expressed as absolute and relative frequencies.

\section{Results}

A total of 37 patients ( 24 women and 13 men) were included in the study. The average age was $40.4 \pm 9.4$ years, ranging from 19 to 65 years (Table 1). Eight patients did not have a previous history of headache and were not patients of our center. They did seek help for the first time. The remaining 29 were migraineurs and had a severe headache for at least

Table 1 Distribution of sex and age of refractory COVID or postCOVID headache in 29 migraine patients and 8 without previous headache

\begin{tabular}{|c|c|c|c|}
\hline \multirow[t]{2}{*}{ Variables } & \multicolumn{2}{|l|}{ Groups } & \multirow[t]{2}{*}{$p$ value } \\
\hline & $\begin{array}{l}\text { Migraineurs } \\
n=29\end{array}$ & $\begin{array}{l}\text { Without previous } \\
\text { headache } \\
n=8\end{array}$ & \\
\hline \multicolumn{4}{|l|}{ Sex } \\
\hline Female $(n ; \%)$ & $19(65.5)$ & $5(62.5)$ & $0.998^{\mathrm{b}}$ \\
\hline Male $(n ; \%)$ & $10(34.5)$ & $3(37.5)$ & \\
\hline \multicolumn{4}{|l|}{ Age } \\
\hline Average (SD) & $40.8(9.4)$ & $38.9(9.8)$ & $0.615^{\mathrm{a}}$ \\
\hline Variation & $19-65$ & $29-56$ & \\
\hline
\end{tabular}

$S D$ standard deviation, $N A$ not applicable

${ }^{\text {a }}$ student's $t$-test $p$ value for mean difference of unpaired samples

${ }^{\mathrm{b}} p$ value based on Fisher's exact test for mean difference of unpaired samples 
three followed days during COVID-19 acute phase $(n=21)$ or started a daily headache for at least three followed days after a minimum of 10 days having tested positive for SarsCov-2 $(n=8)$. Both groups were not responding to their usual migraine symptomatic medication or to a medication prescribed by general practitioners specifically for the headache itself.

Migraine patients used preventive treatment with several options. Sixteen of them had daily headache of moderate to severe intensity within 2 days after a positive test for Coronavirus ( 5 with headache and mild airway symptoms and 11 with isolated headache). The other 13 migraine patients reported a headache that started after 10-16 days of testing positive for Coronavirus and they had, during the acute phase, mild or moderate respiratory symptoms. Four patients seek help at local hospitals during the acute phase.

Among the 8 patients without migraine, 5 (62.5\%) had a severe headache during the acute phase and 3 after 10-13 days thereafter. All of them received metamizole and / or NSAID other than indomethacin. Three patients also received oral prednisone and five patients went to local hospitals for receiving care.

Indomethacin was prescribed for all patients. Thirty-six patients reported greater than $50 \%$ headache relief from the third day and 5 became asymptomatic on the fifth day. One patient, a 36-year-old female with a previous history of migraine did not refer any improvement. She was later diagnosed with pachymeningitis and treated with steroids.

All 37 patients had a normal neurological examination, and none had abnormal oxygen saturation, fever, or any other physical abnormality. However, nearly half referred moderate or severe asthenia. All patients who seek help in local hospitals had their D-dimer measured and none presented abnormalities.

The distribution of the clinical characteristics of refractory COVID or post-COVID headache in 29 migraine patients and 8 without previous headache is summarized in Tables 2, 3 .

\section{Discussion}

COVID-19 or post-COVID-19 headache is a bothersome symptom and may be the only COVID-19 symptom $[1,6]$. However, headache is also a symptom commonly reported in various viral infections such as dengue and chikungunya that are common in the tropical regions and therefore may not be specific for COVID-19 [18, 19]. Although the headache prevalence in COVID varies with different geographic regions, it may occur in higher than one third of the patients $[2,4,6]$.

The true prevalence of headache in COVID patients is uncertain. In a review of 78 studies consisting of 104,751
Table 2 Clinical characteristics of refractory COVID or post-COVID headache and therapeutic response to indomethacin in 29 migraine patients and 8 without previous headache

\begin{tabular}{|c|c|c|c|c|c|}
\hline \multirow[t]{3}{*}{ Characteristics } & \multicolumn{4}{|c|}{ Groups } & \multirow[t]{3}{*}{$p$ value } \\
\hline & \multicolumn{2}{|c|}{ Migraineurs } & \multicolumn{2}{|c|}{$\begin{array}{l}\text { Without previous } \\
\text { headache }\end{array}$} & \\
\hline & $n$ & $\%$ & $n$ & $\%$ & \\
\hline \multicolumn{6}{|l|}{ Headache onset } \\
\hline Within $72 \mathrm{~h}$ & 21 & 72.4 & 5 & 62.5 & 0.672 \\
\hline After 10 days & 8 & 27.6 & 3 & 37.5 & \\
\hline \multicolumn{6}{|c|}{ Improvement over $50 \%$ with 3 days } \\
\hline Yes & 28 & 95.6 & 8 & 100.0 & 1.000 \\
\hline No & 1 & 3.4 & 0 & 0.0 & \\
\hline \multicolumn{6}{|c|}{ Asymptomatic with 5 days } \\
\hline Yes & 20 & 69.0 & 6 & 75.0 & 1.000 \\
\hline No & 9 & 31.0 & 2 & 25.0 & \\
\hline \multicolumn{6}{|c|}{ They received hospital care } \\
\hline Yes & 4 & 13.8 & 5 & 62.5 & 0.011 \\
\hline No & 25 & 86.2 & 3 & 37.5 & \\
\hline
\end{tabular}

$p$ values were calculated using Fisher's exact test

COVID-19 patients, headache was reported in 26,464 patients with a cumulative prevalence of $25.26 \%$ [20].

The headache location is also varied. Up to $2 \%$ of sufferers had a temporal headache, while $35.3 \%$ complained of frontal and $23.5 \%$ had retro-orbital headache. Up to $39.2 \%$ reported diffuse headache [21]. The quality of the headache may also be differently reported by the patients. In a study, which involved 46 patients, $86 \%$ had tensiontype pain and $14 \%$ had migraine-like headache [22]. It was not clear whether patients had a previous history of headache attacks. In addition, not all patients refer severe headache [23, 24].

No clear mechanisms have been reported on how these headaches emerge in COVID-19 patients [25, 26]. However, it has been proposed that the activation of trigeminal nerve ending in the periphery followed by the sensitization of various sites in the brain is one of the main pathophysiological features of headache in these patients $[25,26]$.

The treatment of headache in COVID-19 patients may be difficult [6]. There is no consensus on drugs for this specific type of headache and numerous drugs have been tried with anecdotal results [6]. In a case report, a chronic migraine patient already in use of fremanezumab with comorbidities COVID-19, had a refractory headache. After the use of numerous drugs, she received lacosamide IV and other pharmacological agents with supposed amelioration [27]. Non-steroidal anti-inflammatory drugs were initially contraindicated for COVID-19 patients by the World Health Organization (WHO), but soon after the contraindication was retracted [28]. 
Table 3 Clinical characteristics of refractory COVID or post-COVID headache in 29 migraine patients infected with Sars-CoV-2

\begin{tabular}{lll}
\hline Variables & & \\
\hline Age of onset of pain (years) & $21.1(10.5)$ & \\
$\quad$ Average (SD) & $8-50$ & \\
Variation & & 55.2 \\
Headache characteristics $(n ; \%)$ & 16 & 44.8 \\
$\quad$ Intense daily headache within 2 days (5 with headache and mild airway & \\
$\quad$ symptoms and 11 with isolated headache) & 13 & 3.5 \\
Headache that started after 10-16 days & & 24.1 \\
Prophylactic medications $(n ; \%)$ & 1 & 6.9 \\
Candesartan & 7 & 13.8 \\
Divalproate & 2 & 34.5 \\
Divalproate and atenolol & 4 & 17.2 \\
Divalproate and candesartan & 10 & \\
Nortriptyline, flunarizine and tizanidine & 5 & \\
Topiramate and nortriptyline & & \\
\end{tabular}

Although with retrospective and open design, our study suggests that indomethacin may be useful for these patients. Indomethacin was already suggested as a useful treatment not only for COVID-19 headache, but, in addition, for COVID-19 induced dry cough [29].

Moreover, the contagion of COVID-19 leads to a burst release of the cytokines that may increase the severity of the infection mainly due to heightened immunopathogenicity. The pro-inflammatory metabolites, COX-2, cPLA2, and 5-LOX enzymes involved in their generation, and the substrates that instigate the origination of the innate inflammatory response therefore play an important role in intensifying and worsening of the tissue morbidity related to the coronavirus infection. Drugs with potential for inhibiting these overexpressed immunogenic pathways in the tissues invaded by coronaviruses has been a matter of debate since the inception of the pandemic. The effectiveness of NSAIDs such as Indomethacin in COVID-19 coagulopathy, discouraging the SARS viral replication, the inflammasome deactivation, and synergistic inhibition of $\mathrm{H} 5 \mathrm{~N} 1$ viral infection with representative antiviral drugs, have provided a silver lining in adjuvant COVID-19 therapy [30, 31].

In addition, indomethacin exerts its anti-inflammatory actions though the inhibition of TNF, IL-6 and superoxide free radicals besides the inhibition of COX-1 and-2. Since it also inhibits viral protein synthesis and has been studied against herpes virus 6 , cytomegalovirus and hepatitis B virus, a possible action against SARS-Cov- 2 has been considered. In vitro and in vivo studies, indomethacin reduced viral RNA synthesis in SARS-Cov of monkey vero cells and in canine infections [32].

The main reason why we chose indomethacin to these patients was the lack of efficacy referred by all when treating their headache with metamizole (usually prescribed in Brazil for COVID-19 patient with headache), paracetamol, other NSAID and triptans, which were used by the patients with comorbid migraine. Additionally, indomethacin is an inexpensive and readily available drug with demonstrated efficacy in numerous headache syndromes [7].

The use of 5-day cycle of indomethacin $50 \mathrm{mg}$ BID may have ended the headache or was only a coincidence. We cannot assure that indomethacin was the responsible for alleviating the headache, which could have been demonstrated with a placebo-controlled study.

\section{Conclusions}

In patients with migraine or no prior history of headache who present with refractory COVID or post-COVID headache to common analgesics, anti-inflammatory drugs, and/ or triptans, indomethacin should be considered a therapeutic option.

Funding This research received no specific grant from any funding agency in the public, commercial, or not-for-profit sectors.

\section{Declarations}

Conflict of interest The authors declare that they have no conflict of interest.

Ethical approval All procedures performed in studies involving human participants were in accordance with the ethical standards of the institutional and/or national research committee and with the 1964 Helsinki declaration and its later amendments or comparable ethical standards.

Informed consent Informed consent was obtained from all participants. 


\section{References}

1. Shehata GA, Lord KC, Grudzinski MC, Elsayed M, Abdelnaby R, Elshabrawy HA (2021) Neurological complications of COVID19: underlying mechanisms and management. Int J Mol Sci 22(8):4081

2. Vehar S, Boushra M, Ntiamoah P, Biehl M (2021) Post-acute sequelae of SARS-CoV-2 infection: caring for the 'long-haulers.' Cleve Clin J Med 88:267-272

3. Lechien JR, Chiesa-Estomba CM, De Siati DR, Horoi M, Le Bom SD, Rodriguez A et al (2020) Olfactory and gustatory dysfunctions as a clinical presentation of mild-to-moderate forms of the coronavirus disease (COVID-19): a multicenter European study. Eur Arch Otorhinolaryngol 277(8):2251-2261

4. Kim ES, Chin BS, Kang CK, Kim NJ, Kang YM, Choi JP et al (2020) Clinical course and outcomes of patients with severe acute respiratory syndrome coronavirus 2 infection: a preliminary report of the first 28 patients from the Korean cohort study on COVID19. J Korean Med Sci 35(13):e142

5. Liang WH, Guan WJ, Li CC, Li YM, Liang HR, Zhao Y et al (2020) Clinical characteristics and outcomes of hospitalized patients with COVID-19 treated in Hubei (epicentre) and outside Hubei (non-epicentre): a nationwide analysis of China. Eur Respir J 55(6):2000562

6. Machado FC, Carone Neto G (2021) Carone RSD (2021) Sphenopalatine ganglion block for refractory COVID19 headache: a descriptive case series. Braz J Anesthesiol S0104-0014(21):00189-00195

7. Lucas S (2016) The pharmacology of indomethacin. Headache 56(2):436-446

8. Summ O, Andreou AP, Akerman S, Holland PR, Hoffmann J, Goadsby PJ (2021) Differential actions of indomethacin: clinical relevance in headache. Pain 162(2):591-599

9. Akerman S, Karsan N, Bose P, Hoffmann JR, Holland PR, Romero-Reyes $M$ et al (2019) Nitroglycerine triggers triptanresponsive cranial allodynia and trigeminal neuronal hypersensitivity. Brain 142(1):103-119

10. Iversen HK, Olesen J (1994) Nitroglycerin-induced headache is not dependent on histamine release: support for a direct nociceptive action of nitric oxide. Cephalalgia 14(6):437-442

11. Akerman S, Williamson DJ, Kaube H, Goadsby PJ (2002) The effect of antimigraine compounds on nitric oxide-induced dilation of dural meningeal vessels. Eur J Pharmacol 452(2):223-228

12. Summ O, Andreou AP, Akerman S, Goadsby PJ (2010) A potential nitrergic mechanism of action for indomethacin, but not of other COX inhibitors-relevance to indomethacin-sensitive headaches. J Headache Pain 11(6):477-483

13. Gonzalez-Martinez A, Planchuelo-Gómez Á, Guerrero ÁL, García-Azorín D, Santos-Lasaosa S, Navarro-Pérez MP et al (2021) Evaluation of the impact of the COVID-19 lockdown in the clinical course of migraine. Pain Med 28:449

14. Gentile E, Delussi M, Abagnale C, Caponnetto V, De Cesaris F, Frattale I et al (2021) Migraine during COVID-19: data from second wave pandemic in an Italian cohort. Brain Sci 11(4):482

15. Uygun Ö, Ertaş M, Ekizoğlu E, Bolay H, Özge A, Kocasoy Orhan E et al (2020) Headache characteristics in COVID-19 pandemic a survey study. J Headache Pain 21(1):121

16. Al-Hashel JY, Ismail II (2020) Impact of coronavirus disease 2019 (COVID-19) pandemic on patients with migraine: a web-based survey study. J Headache Pain 21(1):115
17. Headache Classification Subcommittee of the International Headache Society (2018) The international classification of headache disorders, 3rd edition. Cephalalgia 38:1-211

18. Harapan H, Michie A, Sasmono RT, Imrie A (2020) Dengue: a minireview. Viruses 12(8):829

19. Harapan H, Michie A, Mudatsir M, Nusa R, Yohan B, Wagner AL et al (2019) Chikungunya virus infection in Indonesia: a systematic review and evolutionary analysis. BMC Infect Dis 19(1):243

20. Mutiawati E, Syahrul S, Fahriani M, Fajar JK, Mamada SS, Maliga HA et al (2021) Global prevalence and pathogenesis of headache in COVID-19: a systematic review and meta-analysis. F1000Research 9:1316

21. Zayet S, Kadiane-Oussou NJ, Lepiller Q, Zahra H, Royer PY, Toko L et al (2020) Clinical features of COVID-19 and influenza: a comparative study on Nord Franche-Comte cluster. Microbes Infect 22(9):481-488

22. Vacchiano V, Riguzzi P, Volpi L, Tappatà M, Avoni P, Rizzo G et al (2020) Early neurological manifestations of hospitalized COVID-19 patients. Neurol Sci 41(8):2029-2031

23. Tian S, Chang Z, Wang Y, Wu M, Zhang W, Zhou G et al (2020) Clinical characteristics and reasons for differences in duration from symptom onset to release from quarantine among patients with COVID-19 in Liaocheng. China Front Med (Lausanne) 7:210

24. Huang R, Zhu L, Xue L, Liu L, Yan X, Wang J et al (2020) Clinical findings of patients with coronavirus disease 2019 in Jiangsu province, China: a retrospective, multi-center study. PLoS Negl Trop Dis 14(5):e0008280

25. Bolay H, Gül A, Baykan B (2020) COVID-19 is a real headache! Headache 60(7):1415-1421

26. Ong JJY, Bharatendu C, Goh Y, Tang JZY, Sooi KWX, Tan YL et al (2020) Headaches associated with personal protective equipment - a cross-sectional study among frontline healthcare workers during COVID-19. Headache 60(5):864-877

27. Arca KN, Starling AJ (2020) Treatment-refractory headache in the setting of COVID-19 pneumonia: Migraine or meningoencephalitis? Case report. SN Compr Clin Med. https://doi.org/10.1007/ s42399-020-00369-y

28. World Health Organization. Clinical management of severe acute respiratory infection when novel coronovirus (nCoV) infection is suspected. Available in: <https://www.who.int/publications/i/ item/10665-332299>. Accessed 24 May 2021.

29. Alkotaji M, Al-Zidan RN (2021) Indomethacin: can it counteract bradykinin effects in COVID-19 patients? Curr Pharmacol Rep $22: 1-5$

30. Prasher P, Sharma M, Gunupuru R (2021) Targeting cyclooxygenase enzyme for the adjuvant COVID-19 therapy. Drug Dev Res. https://doi.org/10.1002/ddr.21794

31. Ho P, Zheng J-Q, Wu C-C, Hou YC, Liu WC, Lu C-L et al (2021) Perspective adjunctive therapies for COVID-19: beyond antiviral therapy. Int J Med Sci 18:314-324

32. Amici C, Di Caro A, Ciucci A, Chiappa L, Castilletti C, Martella $\mathrm{V}$ et al (2006) Indomethacin has a potent antiviral activity against SARS coronavirus. Antivir Ther 11(8):1021-1030

Publisher's Note Springer Nature remains neutral with regard to jurisdictional claims in published maps and institutional affiliations. 